American Journal of Infectious Diseases 7 (2): 40-44, 2011

ISSN 1553-6203

(C) 2011 Science Publications

\title{
Genetic Polymorphisms in the Fat Mass and Obesity-Associated Gene Confers Risk of Obesity in Iraqi Population
}

\author{
Shatha Ramadhanzaidan, Faris Abd Al Kareem \\ and Lujain Anwar Alkhazrajy \\ Obesity Research and Therapeutic Unit, \\ Al-Kidney Medical College, Baghdad University, Iraq
}

\begin{abstract}
Problem statement: Obesity is strongly influenced by genetic factors, with an estimated heritability of $60 \%$ BMI. Genetic susceptibility to the common form of obesity appears to be polygenic. Although theoretical analyses emphasized the power of genetic association study in common polygenic diseases, the search for genes conferring the risk of obesity has thus far not been very successful. Approach: In this research, DNA was extracted from 100 individuals who diagnosed as diabetes mellitus and have obesity referred to Al-Kindy research and therapeutic unit and in Baghdad 40 subject used as control. Thirty cycles of PCR were performed on exons 2 and 3 of the FSHß gene, which encode for the translated FSH 3 protein. Results: For each exon, 30 cycles of PCR were performed at $95^{\circ} \mathrm{C}$ for $1 \mathrm{~min}, 55^{\circ} \mathrm{C}$ for $30 \mathrm{sec}$ and $72^{\circ} \mathrm{C}$ for $30 \mathrm{sec}$. Samples were subjected to sequencing and the results showed that the signals were poor and there is no capability to analyze so, we were recommended to do cloning the fragment of DNA to gain good signals. We did not observe significant association between rs9939609 and type 2 diabetes. Conclusion: Two SNPs (rs16952777 and rs1107355) in LD block 1 were nominally associated with type 2 diabetes. SNPs in the same block were also nominally associated with fasting glucose concentrations in no diabetic subjects (control subject). However, none of these associations remained significant after adjustment for multiple testing.
\end{abstract}

Key words: Same block, associations remained, remained significant, nominally associated, results showed, diabetic subjectsm, genetic association, genes conferring, estimated heritability

\section{INTRODUCTION}

Obesity is strongly influenced by genetic factors, with an estimated heritability of $60 \%$ BMI (ElNabarawy et al., 2010; Souren et al., 2007). Genetic susceptibility to the common form of obesity appears to be polygenic. Although theoretical analyses emphasized the power of genetic association study in common polygenic diseases, the search for genes conferring the risk of obesity has thus far not been very successful. A few reported associations with genes such as GAD2, ENPP1 and INSIG2 also yielded inconsistent results in replication efforts (Boutin et al., 2003; Meyre et al., 2005; American Diabetes Association, 2011; Herbert et al., 2006). Recently, several independent studies using different approaches reported strong associations of genetic variants in the Fat mass and Obesity-Associated (FTO) gene with obesity in populations of European origin (Frayling et al., 2007; Dina et al., 2007).

Zeggini et al. (2007) initially found the association of FTO genetic variants with type 2 diabetes in a genome-wide association study for type 2 diabetes. However, the association was abolished by adjustment for BMI, indicating that the association with type 2 diabetes was mediated through an effect of obesity (Zeggini et al., 2007; Yuan et al., 2006). They replicated the associations (rs9939609) with obesity in a total of 38,759individuals (Frayling et al., 2007).

Dina et al. (2007) concurrently reported strong associations of single-nucleotide polymorphisms (SNPs) (rs1421085 and rs17817449) of the FTO gene with childhood and severe adult obesity.

Two other genome-wide association studies (Scuteri et al., 2007; Hinney et al., 2007) also independently reported the associations of nearby FTO genetic variants (rs9930506, rs8050136, rs7193144,

Corresponding Author: Shatha Ramadhanzaidan, Obesity Research and Therapeutic Unit, Al-Kindy Medical College,

Baghdad University, Iraq 
rs1121980 and rs9939973) with obesity and obesityrelated traits in European and Hispanic populations. All these SNPs fall in a region of strong Linkage Disequilibrium (LD) in intron 1 of the FTO gene (Gibbs et al., 2003). The effect of FTO genetic variants on common obesity is also substantial in the European population.

Adults who are homozygous for the risk-conferring rs9939609 A allele weighed $3 \mathrm{~kg}$ more and had a 1.67fold increased odds ratio of obesity when compared with those without a risk allele (Frayling et al., 2007; Barrett et al., 2005).

The calculated population-attributable risk is $22 \%$ for common obesity in populations of European origin (Frayling et al., 2007; Matthews et al., 1985). Reproducibility is essential for reported genetic associations, especially among populations of different ethnic backgrounds. However, studies in an Oceanic population (Ohashi et al., 2007), African Americans (Hinney et al., 2007), Han Chinese (Li et al., 2008; Shahwan-Akl, 2010) and Japanese (Horikoshi et al., 2008; Purcell et al., 2007) failed to detect associations between previously reported SNPs and obesity or obesity-related traits.

Although the limited sample size and power of these studies is the most likely reason for the lack of association, there is emerging evidence showing that other FTO SNPs not in LD with rs9939609 may be the causative variant in non-European populations (Grant et al., 2008).

This study introduces a new investigation of the association of FTO genetic variants with obesity and type 2 diabetes of Iraqi population. Instead of testing only a few variants, we used a gene based approach Neale and Sham (2004); Tabor et al. (2002) and Purcell et al. (2003) by selecting potentially functional and common SNPs from the 3_end of the neighboring. RPGRIP1L gene to the 5_flanking region of the FTO gene. Their associations with obesity-related quantitative metabolictraitswere also analyzed.Toexamine the association of fat mass-and obesity associated (FTO) gene variant with obesity in Iraqi diabetic obese patients.

\section{MATERIALS AND METHODS}

Subject: One hundred and 6 subject individuals age range (15-50) years who participate in this study to fill from individuals questionnaire.

DNA analysis: DNA was extracted from 100 individuals who diagnosed as diabetes mellitus and have obesity refer to Al-Kindy research and therapeutic unit in Baghdad 40 subject used as control. Thirty cycles of PCR were performed as described previouslyon exons 2 and 3 of the FSHB gene, which encode forthe translated FSHß protein. For each exon, 30cycles of PCR were performed at $95^{\circ} \mathrm{C}$ for $1 \mathrm{~min}$, $55^{\circ} \mathrm{C}$ for $30 \mathrm{sec}$ and $72^{\circ} \mathrm{C}$ for $30 \mathrm{sec}$. The $\mathrm{MgCl}_{2}$ concentration was $2.0 \mathrm{mMfor}$ exon 2 and $2.5 \mathrm{mM}$ for exon 3. Primer sequences include: Exon 2 sense (AGT TTC TAG TGG GCT TCA TTG TTT G) exon 2 antisense (TGG CTA AAG GAC TCA TGG CTG); exon 3 sense (GCT AAA TAG GAACTT CCA C) and exon 3 antisense (TAT GTG GCC TGA AAT GTC C). A negative control, containing all reagents except DNA, was included in each PCR. The PCR products were then electrophoreses on agarose gels, ethanol precipitated and subjected to dideoxy DNA sequencing using Big Dye Terminator Cycle (ABI Prism, PE Applied Bios stems, Foster City, CA).

Sequencing reactions were done using the ABI Big Dye Terminator kit (PE Applied Bios stems). Briefly, duplicate reactions of $20 \mathrm{ng}$ template of the PCR products were amplified in a totalreaction volume of 20 $\mu \mathrm{L}$ using either a forward or reverse primer. After the sequencing amplification, unincorporated nucleotides and primers were removed by spin column chromatography (Princeton Separations, Trenton, NJ) and dried in a vacuum centrifuge. Template suppression reagent was added to each of the samples, which were then vortexes briefly and denatured at $95 \mathrm{C}$ for $2 \mathrm{~min}$.

Samples were immediately placed on ice for $2 \mathrm{~min}$ and vortexedagain to mix. Then, the samples were analyzed on the ABI 310Automated DNA Sequencer (ABI Prism, PE Applied Bios stems).

Sequencing was confirmed in forward and reverse directions three times each for both probands and the parents.

Sequences analysis: Samples were subjected to sequencing (Bioneer, Korea) and the results showed that the signals were poor and there is no capability to analyze so, we were recommended to do cloning the fragment of DNA to gain good signals as shown in Fig 1-2.

\section{RESULTS}

Basic demographic data, SNP information and structure of LD. The baseline characteristics of participants are shown in Table 1 and 2 (Souren et al., 2007). Graphical representation of SNPs in relation to the exon-intron PCR product show a band within a 419-kb region containing the FTO gene using genotype data from the $\mathrm{CHB}$ and $\mathrm{CEU}$ HapMap samples. 
Am. J. Infect. Dis., 7 (2): 40-44, 2011

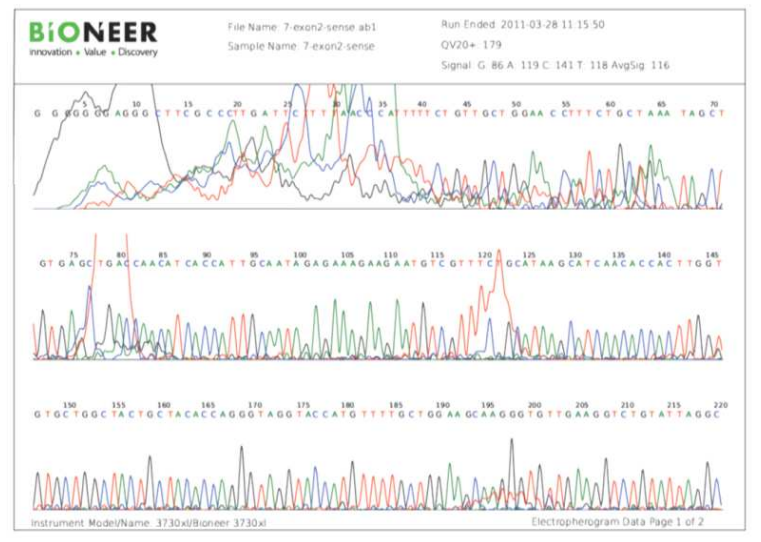

Fig. 1: Fragment of DNA

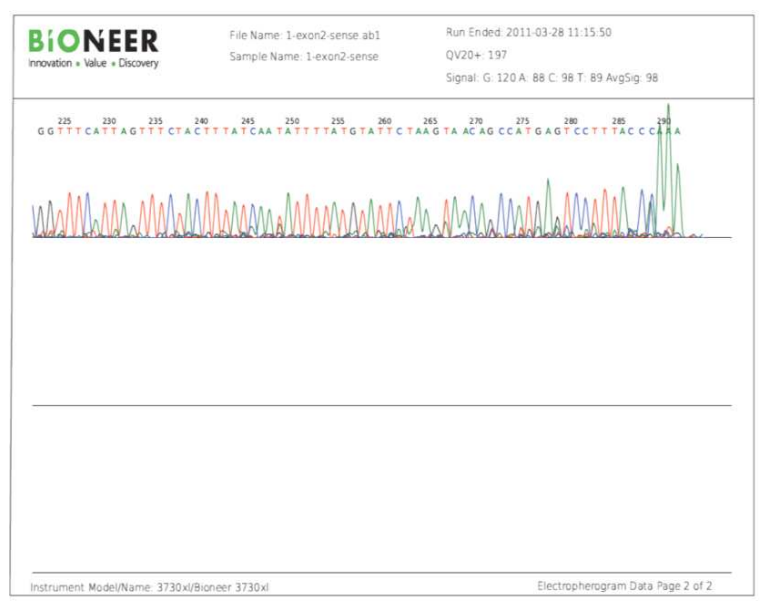

Fig. 2: Fragment of DNA

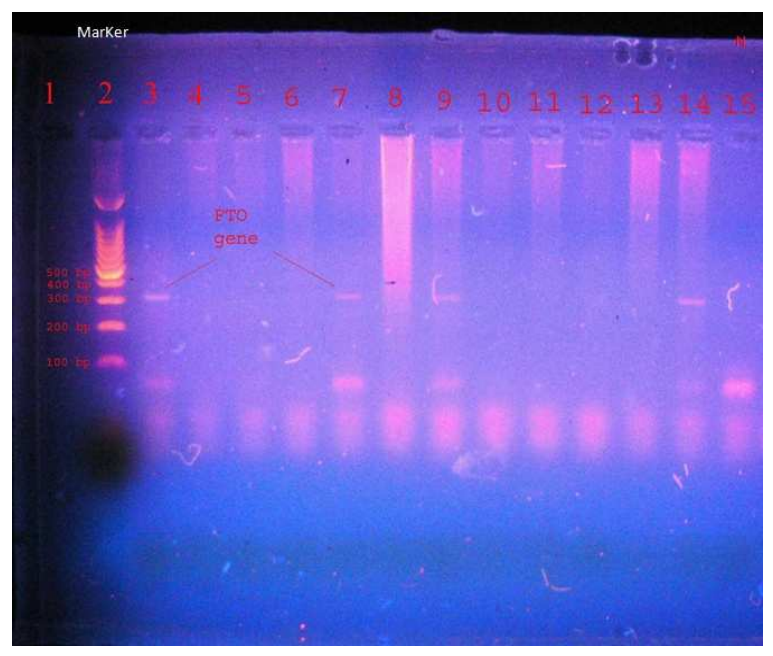

Fig. 3: PCR product of (FTO) gene electrophoresis on agarose gel (2\%), $45 \mathrm{~min} / 70$ volt
Table 1: BMI for individual participants

\begin{tabular}{lrrrrrrr}
\hline No & BMI & No & BMI & No & BMI & No & BMI \\
\hline 1 & 38.0 & 27 & 26.6 & 57 & 29.3 & 83 & 29.0 \\
2 & 34.1 & 28 & 26.3 & 58 & 2.7 & 84 & 29.7 \\
3 & 31.4 & 29 & 35.2 & 59 & 27.8 & 85 & 28.5 \\
4 & 27.8 & 30 & 25.0 & 60 & 30.3 & 86 & 30.3 \\
5 & 33.3 & 31 & 23.7 & 61 & 25.8 & 87 & 34.1 \\
6 & 20.1 & 32 & 18.0 & 62 & 30.0 & 88 & 25.8 \\
7 & 29.0 & 33 & 27.0 & 63 & 28.6 & 89 & 33.1 \\
8 & 31.4 & 34 & 34.0 & 64 & 28.0 & 90 & 28.8 \\
9 & 23.0 & 35 & 39.5 & 65 & 44.7 & 91 & 36.8 \\
10 & 24.8 & 36 & 41.3 & 66 & 30.0 & 92 & 42.5 \\
11 & 27.5 & 37 & 38.5 & 67 & 30.3 & 93 & 33.3 \\
12 & 22.8 & 38 & 32.6 & 68 & 28.7 & 94 & 25.8 \\
13 & 24.1 & 39 & 19.6 & 69 & 27.3 & 95 & 25.4 \\
14 & 32.8 & 40 & 19.6 & 70 & 34.0 & 96 & 30.1 \\
15 & 30.0 & 41 & 22.2 & 71 & 28.6 & 97 & 34.8 \\
16 & 35.7 & 42 & 28.8 & 72 & 33.3 & 98 & 30.8 \\
17 & 27.4 & 43 & 35.4 & 73 & 27.3 & 99 & 32.9 \\
18 & 30.7 & 44 & 35.1 & 74 & 31.2 & 100 & 25.9 \\
19 & 29.1 & 45 & 26.7 & 75 & 29.3 & 101 & 27.3 \\
20 & 25.0 & 50 & 42.0 & 76 & 25.3 & 102 & 21.5 \\
21 & 28.0 & 51 & 31.8 & 77 & 30.2 & 103 & 28.0 \\
22 & 28.5 & 52 & 32.2 & 78 & 25.6 & 104 & 26.3 \\
23 & 31.2 & 53 & 36.8 & 79 & 31.0 & 105 & 30.9 \\
24 & 25.0 & 54 & 26.4 & 80 & 31.0 & 106 & 32.0 \\
25 & 37.5 & 55 & 28.8 & 81 & 30.3 & 107 & \\
26 & 34.6 & 56 & 27.8 & 82 & 25.8 & 108 & \\
\hline & & & & & & &
\end{tabular}

Table 2: The reaction was carried out as following:

\begin{tabular}{|c|c|c|}
\hline \multirow[b]{2}{*}{ Step temperature } & \multicolumn{2}{|c|}{ PCR with FTO primes } \\
\hline & \multicolumn{2}{|c|}{ Time no of cycles } \\
\hline Denaturation 1 first loop & $95^{\circ} \mathrm{C}$ & 3 min 1 cycle \\
\hline Denaturation 2 & $94^{\circ} \mathrm{C}$ & $1 \mathrm{~min} 30$ cycles \\
\hline Annealing & $62^{\circ} \mathrm{C}$ & $1 \mathrm{~min}$ \\
\hline Extension 1 & $72^{\circ} \mathrm{C}$ & $1 \mathrm{~min}$ \\
\hline Extension 2 & $72^{\circ} \mathrm{C}$ & 5 min 1 cycle \\
\hline
\end{tabular}

Figure 3 shows association analysis of genetic variants of the FTO gene with obesity and BMI.

\section{DISCUSSION}

The rs9939609 A allele was identified as the risk variant for obesity in populations of European ancestry (Frayling et al., 2007). Among the 19 SNPs in this study, the rs9939609 A allele was strongly associated with obesity (P-7.0-10-4). The per-a allele increase of odds ratio for obesity was 1.43 (95\% CI 1.16-1.75). The association remained significant after correction for multiple testing. The genotypic odds ratio for obesity was 2.60(1.24-5.46) (P-0.011) for the AA genotype and 1.32 (1.05-1.66) (P-0.018) for the AT genotype. The genetic model was best fit with an additive model (P-7.0-10-4). 0.0098 and 0.014 for additive, recessive and dominant model, respectively). When different criteria for obesity were applied (16-24), the associations were also significant (allelic P-7.6-10-4 for obesity defined as BMI _28 $\mathrm{kg} \mathrm{m}^{-1}$ and 0.0081 for BMI $27 \mathrm{~kg} \mathrm{~m}^{-1}$ ). 
The frequency of the rs9939609 A allele (12.6\%) was substantially lower in our study than that of European populations (45\%) (Frayling et al., 2007), corresponding to a lower population-attributable risk fraction of $8.7 \%$ in the Chinese population. The rs9939609 A allele was also associated with increased BMI (P_0.0024) and weight (P-0.0065).

In our study cohort, carriers with AA genotype ((means SD) BMI $31.528 .76 \mathrm{~kg} \mathrm{~m}^{-1}$ ) and AT genotype $\left(28.757 .89 \mathrm{~kg} \mathrm{~m}^{-1}\right)$ were heavier than those with TT genotypes $\left(28.088 .45 \mathrm{~kg} \mathrm{~m}^{-1}\right)(\mathrm{P}-0.0088$ and 0.048 , respectively).

The genetic model was best fit with an additive genetic model (P-0.0024, 0.0091 and 0.073 for additive, recessive and dominant models, respectively). Each additional copy of the rs9939609 a allele was associated with a BMI increase of a mean $0.124 \mathrm{Z}$ score units, equivalent to $-0.37 \mathrm{~kg} \mathrm{~m}^{-1}$ or 1.07 $\mathrm{kg}$ body wt for a person $1.7 \mathrm{~m}$ tall.

The extent of variance in BMI explained by rs99399609 was $0.5 \%$ in the Chinese population. There was no heterogeneity in the per- a allele increase of odds ratio for obesity and effect size on BMI among different study populations. We did not detect any significant interaction between rs9939609 genotype and age or sex on the risk of obesity or BMI.

Association analysis of genetic variants of the FTO gene with type 2 diabetes: It not observes significant association between rs9939609 and type 2 diabetes. Two SNPs (rs16952777 and rs1107355) in LD block 1 were nominally associated with type 2 diabetes. SNPs in the same block were also nominally associated with fasting glucose concentrations in no diabetic subjects (control subject). However, none of these associations remained significant after adjustment for multiple testing.

\section{CONCLUSION}

According to the samples were tested, it can be concluded that there is no significant association between rs9939609 and type 2 diabetes. Two SNPs (rs16952777 and rs1107355) in LD block 1 were nominally associated with type 2 diabetes. SNPs in the same block were also nominally associated with fasting glucose concentrations in no diabetic subjects (control subject). However, none of these associations remained significant after adjustment for multiple testing.

Also, samples were subjected to sequencing showed that the signals were poor and there is no capability to analyze so, it is recommended to do cloning the fragment of DNA to gain good signals.

\section{REFERENCES}

American Diabetes Association, 2011. Standards of Medical Care in Diabetes. Diabetes Care, 34: S11S61. DOI: $10.2337 / \mathrm{dc} 11-S 011$

Barrett, J.C., B. Fry, J. Maller and M.J. Daly, 2005. Haploview: Analysis and visualization of LD and haplotype maps. Bioinformatics, 21: 263-265. DOI: 10.1093/bioinformatics/bth457

Boutin, P., C. Dina, F. Vasseur, S. Dubois and L. Corset et al., 2003. GAD2 on chromosome 10p12 is a candidate gene for human obesity. PLoS. Biol., 1: E68-E68. DOI: 10.1371/journal.pbio.0000068

Dina, C., D. Meyre, S. Gallina, E. Durand and A. Korner et al., 2007. Variation in FTO contributes to childhood obesity and severe adult obesity. Nat. Genet., 39: 724-726. PMID: 17496892

El-Nabarawy, S.K., M.A.E. Mohamed, M.M. Ahmed and G.H. El-Arabi，2010. $\alpha$-lipoic acid therapy modulates serum levels of some trace elements and antioxidants in type 2 diabetic patients. Am. J. Pharmacol. Toxicol., 5: 152-158. DOI: 10.3844/ajptsp.2010.152.158

Frayling, T.M., N.J. Timpson, M.N. Weedon, E. Zeggini and R.M. Freathy et al., 2007. A common variant in the FTO gene is associated with body mass index and predisposes to childhood and adult obesity. Science, 316: 889-894. PMID: 17434869

Gibbs, R.A., J.W. Belmont, P. Hardenbol, T.D. Willis and F. Yu, 2003. The International HapMap Project. Nature, 426: 789-796.

Grant, S.F.A., M. Li, J.P. Bradfield, C.E. Kim and K. Annaiah et al., 2008. Association analysis of the FTO gene with obesity in children of Caucasian and African ancestry reveals a common tagging SNP. PLoS ONE., 3: e1746-e1746. DOI: 10.1371/journal.pone.0001746

Herbert, A., N.P. Gerry, M.B. McQueen, I.M. Heid and A. Pfeufer et al., 2006 . A common genetic variant is associated with adult and childhood obesity. Science, 312: 279-283. DOI: 10.1126/science. 1124779

Hinney, A., T.T. Nguyen, A. Scherag, S. Friedel and G. Bronner et al., 2007. Genome Wide Association (GWA) study for early onset extreme obesity supports the role of fat mass and obesity associated gene (FTO) variants. PLoS. ONE, 2: e1361-e1361. DOI: 10.1371/journal.pone.0001361

Horikoshi, M., K. Hara, C. Ito, N. Shojima and R. Nagai et al., 2007. Variations in the HHEX gene are associated with increased risk of type 2 diabetes in the Japanese population. Diabetologia, 50: 24612466. PMID:17928989 
Li, H., Y. Wu, R.J. Loos, F.B. Hu and Y. Liu et al., 2008. Variants in the fat mass-and obesityAssociated (FTO) gene are not associated with obesity in a chinese han population. Diabetes, 57: 264-268. DOI: $10.2337 / \mathrm{db} 07-1130$

Matthews, D.R., J.P Hosker, A.S. Redenski, B.A. Naylor and D.F. Treacher et al., 1985. Homeostasis model assessment: Insulin resistance and beta-cell function from fasting plasma glucose and insulin concentrations in man. Diabetologia, 28: 412-419. PMID: 3899825

Meyre, D., N.B. Naji, A. Tounian, C. Samson and C. Lecoeur et al., 2005. Variants of ENPP1 are associated with childhood and adult obesity and increase the risk of glucose intolerance and type 2 diabetes. Nat. Genet., 37: 863-867. DOI: $10.1038 / \mathrm{ng} 1604$

Neale, B.M. and P.C. Sham, 2004. The future of association studies: Gene-based analysis and replication. Am. J. Hum. Genet., 75: 353-362.

Ohashi, J., I. Naka, R. Kimura, K. Natsuhara and T. Yamauchi et al., R2007. FTO polymorphisms in oceanic populations. J. Hum. Genet., 52: 10311035. PMID: 17928949

Purcell, S., B. Neale, K. Todd-Brown, L. Thomas and M.A.R. Ferreira et al., 2007. PLINK: A tool set for whole-genome association and population-based linkage analyses. Am. J. Hum. Genet., 81: 559-575. DOI: $10.1086 / 519795$

Purcell, S., S.S. Cherny and P.C. Sham, 2003. Genetic power calculator: Design of linkage and association genetic mapping studies of complex traits. Bioinformatics, 19: 149-150. PMID: 12499305
Scuteri, A., S. Sanna, W.M. Chen, M. Uda and G. Albai et al., 2007. Genome-wide association scan shows genetic variants in the FTO gene are associated with obesity-related traits. PLoS, Genet, 3: e115e115. DOI: 10.1371/journal.pgen.0030115

Shahwan-Akl, L., 2010. Cardiovascular disease risk factors among adult Australian-Lebanese in Melbourne. Int. J. Res. Nurs., 1: 1-7. DOI: 10.3844/ijrnsp.2010.1.7

Souren, N.Y., A.D.C. Paulussen, R.J.F. Loos, M. Gielen and G. Beunen et al., 2007. Anthropometry, carbohydrate and lipid metabolism in the East Flanders prospective twin survey: Heritabilities. Diabetologia, 50: 2107-2116. DOI: $10.2337 / \mathrm{db} 08$ 0377

Tabor, H.K., N.J. Risch and R.M. Myers, 2002. Candidate-gene approaches for studying complex genetic traits: Practical considerations. Nat. Rev. Genet., 3: 391-397. DOI: 10.1038/nrg796

Yuan, H.Y., J.J. Chiou, W.H. Tseng, C.H. Liu and C.K. Liu et al., 2006. FASTSNP: An always up-to-date and extendable service for SNP function analysis and prioritization. Nucl. Acid. Res., 34: W635W641. DOI: 10.1093/nar/gk1236

Zeggini, E., M.N. Weedon, C.M. Lindgren, T.M. Frayling and K.S. Elliott et al., 2007. Replication of genome-wide association signals in UK samples reveals risk loci for type 2 diabetes. Science, 316: 1336-1341.DOI: 10.1126/science. 1142364 